\title{
"MIS" VICO
}

\author{
Giuseppe Cacciatore \\ (Universidad de Nápoles Federico II)
}

Resumen: La pluralidad de Vicos que habitan en Vico no solo se refieren a la multiversalidad del filósofo napolitano, sino, en este caso, a la multidisciplinariedad que caracteriza un «largo habitar» del Autor en las páginas viquianas. Este "habitar" ha estado caracterizado por el empleo de los momentos clave de una filosofía que todavía hoy es capaz de hablar a la contemporaneidad. La razón narrativa del Autor nos conduce historicistamente a través de esos momentos, desvelando las claves de cómo, durante casi medio siglo de «trato con sus páginas», ha llegado el Autor a desentrañar la pluralidad de un Vico en perspectiva.

Palabras clave: Vico, $350^{\circ}$ Aniversario, historicismo, pluralismo, Centro di studi vichiani, G. Cacciatore.

“My" Vicos

ABSTRACT: The plurality of Vicos that inhabit Vico does not only refer to the multiversality of the Neapolitan philosopher, but, in this case, to the multidisciplinar character of the «long living» of the Author in the Viquian pages. This "living" has been characterized by the use of the key moments of a philosophy that is still capable of speaking to contemporaneity. The Author's narrative reason leads us through those moments historicistically, revealing the keys of how, during almost half a century of «dealing with its pages», the Author has come to unravel the plurality of a perspectival Vico.

KeYwords: Vico, $350^{\text {th }}$ Anniversary, historicism, pluralism, Centro di studi vichiani, G. Cacciatore.

\section{ITALIANO}

RIASSUNTO: La pluralità dei Vico che albergano in Vico si riferisce non solo alla multiversalità del filosofo napoletano bensì, in questo caso, anche alla multidisciplinarietà che caratterizza il «lungo abitare» dell'Autore nelle pagine viquiane. Tale "abitare" è stato caratterizzato dall'uso dei momenti chiave di una filosofia che ancora oggi è capace di parlare alla contemporaneità. La ragione narrativa dell'Autore ci conduce storicisticamente attraverso questi momenti, rivelando le chiavi di come, nel corso di quasi mezzo secolo di «confronto con le sue pagine», l'Autore è giunto a sviscerare la pluralità di un Vico in prospettiva.

Parole chiave: Vico, 350 anniversario, storicismo, pluralismo, Centro di studi vichiani, G. Cacciatore.

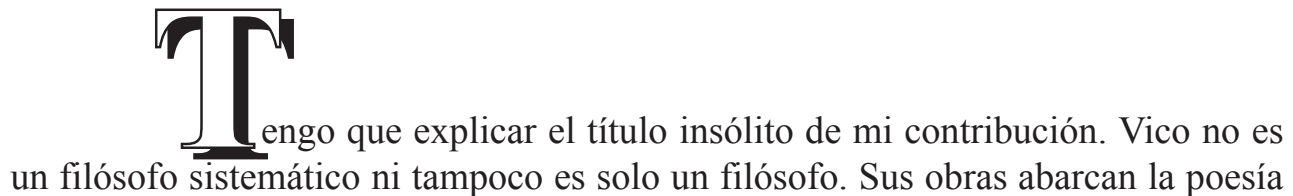

Este artículo responde a una invitación expresa por parte de la Dirección de la Revista para este volumen especial por el $350^{\circ}$ Aniversario del nacimiento de G. Vico, habiendo superado los criterios de valoración y del proceso de aceptación. 
y la oratoria, la retórica y la autobiografía, la historia y la filología, la mitología y las literaturas clásicas, el derecho y la filosofía. Se trata de una actividad poliédrica que, desde hace más de tres siglos, ha ocupado a estudiosos que han cubierto, por decirlo así, todo el arco de las disciplinas humanísticas. Pero si este es el dato objetivo de todo el itinerario de investigación del filósofo napolitano, hay uno subjetivo que obliga al investigador que se acerca a él a adoptar una perspectiva basada en la contaminación de los saberes. Naturalmente se trata de una práctica que se perfecciona y que se enriquece en el curso de los años y que tiene que poseer el carácter de lo permanentemente inacabado. El plural que he usado al principio, sin embargo, concierne de cerca al carácter de mi largo "habitar" la página viquiana, que ha estado caracterizado por el empleo de los momentos clave de una filosofía que todavía hoy es capaz de hablar a la contemporaneidad.

Mi primer encuentro con Vico fue favorecido por la colaboración en el Bollettino del Centro di studi vichiani -que de ahora en adelante citaré con la sigla BCSV - a la que me invitaron Pietro Piovani y Fulvio Tessitore. Se trató, al comienzo, de la redacción de numerosas fichas para el «Avvisatore bibliografico» que se hallaba en el apéndice de la revista. El destino quiso que una de mis primeras publicaciones después de graduarme surgiera de una tarea que me dio Piovani y que consistía en señalar -en ese entonces no había ordenadores ni por supuesto motores de búsqueda- las iniciativas que se habían difundido en el mundo con ocasión del tricentenario del nacimiento de Vico. Pero mi primer estudio verdadero sobre Vico hubo de nacer del intento, que iba creciendo en mí, de hallar puntos de contacto y de diferencia entre las líneas de fondo del historicismo alemán (a partir de Dilthey a quien había dedicado dos volúmenes a mediados de los años Setenta) y el historicismo "de los orígenes" del filósofo napolitano. El núcleo central del mismo trazado que iba de Vico al historicismo crítico, según sugirieron muy acertadamente tanto Paci como Habermas, es la centralidad de la historia de la experiencia humana como relación entre conocer y hacer, tal y como reza el título de un ensayo mío que apareció en el BCSV por el año 1979. Mientras tanto se iban multiplicando mis contactos con filósofos y estudiosos alemanes de Vico: Stephan Otto, Manfred Riedel, Ferdinand Fellmann, Helmut Viechtbauer, Matthias Kaufmann, Jürgen Trabant, en especial con el primero, que había traducido el así llamado Liber metaphysicus, además de haber escrito numerosos ensayos y una monografía sobre Vico que vio la luz también en traducción italiana. Este encuentro provechoso entre estudiosos italianos y alemanes tuvo una ulterior fase de debate con la publicación en el número del BCSV del año 1981 de una sección dedicada a los Materiali su "Vico in Germania", con una introducción mía y de Giuseppe Cantillo y con ensayos de Stephan Otto, Günther Wohlfart y Ferdinand Fellmann.

Después de una serie numerosa de reseñas dedicadas a ensayos y libros acerca de Vico y a algunos momentos de la recepción de Vico en Italia (sobre el 
Vico de Ottavio Colecchi filósofo abruzo-napolitano de las primeras décadas del siglo XIX y sobre las páginas "viquianas" en el libro póstumo de Piovani Scandagli critici) retomé, entre finales de los años Ochenta y comienzos de los Noventa, el análisis y la discusión de las interpretaciones alemanas de Vico. En particular, analicé, en algunos casos concordando, en otros disintiendo, una serie de nuevas investigaciones que Stephan Otto y su escuela habían dedicado a De Antiquissima. Se trata de un intento original, más teoréticamente orientado que filológicamente fundamentado, de localizar una Grundstruktur del pensamiento viquiano en clave filosófico-trascendental. Finalmente, permaneciendo en el marco de la presencia de Vico en la cultura filosófica alemana, se inserta el debate acerca de la primera traducción integral de la Scienza nuova, editada por Vittorio Hösle y Cristoph Jermann. Los textos de la discusión (el mío y los de Donatella Di Cesare, Ferdinand Fellmann, Gonsalv Meinberger y Jürgen Trabant) aparecieron en el n. XXI, 1991, del BCSV. En el mismo número de la revista salía una reseña mía -que me había sugerido justamente Piovani- de una monografía del -en ese entonces- joven estudioso José M. Sevilla (Giambattista Vico: metafísica de la mente e historicismo antropológico. Un estudio sobre la concepción viquiana del hombre, de su mundo y de su ciencia, 1988), que unos años antes ya había publicado algunos ensayos en el BCSV. Además, 1991 es el año de la fundación, por voluntad de J.M. Sevilla y de otros colegas, en la Universidad de Sevilla, del "Centro de Investigaciones sobre Vico", como prueba -según afirmaría yo en un ensayo publicado en España en el año 1994- del hecho de que la literatura crítica española acerca de Vico podía confrontarse sin duda más que dignamente con la historiografía italiana y europea.

Comenzaba de este modo una nueva etapa de mi confrontación con Vico y con sus estudiosos: la presencia del autor de la Scienza nuova en la filosofía española contemporánea (y luego también latinoamericana). En el número del BCSV del año 1994 -el mismo año en que, según la designación de mi maestro Tessitore, asumí la dirección del "Centro di Studi Vichiani”, que mantuve hasta el año 2002salieron publicadas las intervenciones de un encuentro sobre Vico en la cultura española que había tenido lugar en Valencia en 1991 y que había sido organizado por otro apreciado estudioso y editor de Vico, Josep Martínez Bisbal. Entre las intervenciones figuraba un breve ensayo mío sobre Ortega e Vico que, aunque consciente de la escasa consistencia de textos y referencias del filósofo madrileño a la obra viquiana, subrayaba el mérito de este de haber «reabierto algunos senderos de difusión del viquismo en España». Señalaba, además, la acertada intuición orteguiana de una "filosofía mediterránea", la de Vico, de sus sombras y de sus claroscuros, que se contrapone a la luz y a la nitidez conceptual de la "filosofía nórdica" de Kant y de Hegel. No casualmente Vico reaparece, a comienzos de los años Treinta, en las páginas orteguianas dedicadas a Dilthey. Vico anticipa, según Ortega, toda la gran literatura de los siglos XIX-XX acerca de la génesis de la razón histórica, acerca de 
la "posesión de la nueva tierra", esto es, acerca del significado nuevo que adquiere la crítica histórica, centrada en la riqueza de contenidos que conlleva la vida humana y su historia. Significativa es la icástica proposición que es posible leer en las páginas de Historia como sistema (publicada en traducción inglesa en 1935): «El hombre no tiene naturaleza, sino que tiene...historia. O, lo que es igual: lo que la naturaleza es a las cosas, es la historia-como res gestae- al hombre».

Se iba delineando, ya a mediados de los años Noventa, "otro" Vico, hallado gracias al estímulo cultural y científico de uno de los mayores estudiosos alemanes de lingüística y de semiótica: Jürgen Trabant, que había organizado en Berlín un congreso, auspiciado por la Freie Universität, sobre Vico und die Zeichen. En esa ocasión pronuncié una ponencia, luego publicada en el año 1995 en el volumen de las actas, sobre Simbolo e storia tra Vico e Cassirer. Lo que a esa altura me atraía de la articulada y compleja filosofía viquiana era la facultad mítico-simbolizadora y metafórica de la fantasía, leída a la luz de la filosofía de las formas simbólicas. El concepto cassireriano de "forma simbólica" se me antojaba como una exposición sistemática de intuiciones diseminadas en el caos compuesto de la obra viquiana, a partir de la elaboración consciente de una teoría de la historia, alejada de toda hipótesis idealista-trascendental. Justamente porque se atribuye a la fantasía y al pensamiento mítico la facultad de activar procedimientos de orden conceptual, se torna plausible la relación entre metafísica de los principios y empiricidad del mundo humano.

Mientras tanto, durante mi dirección del "Centro di Studi Vichiani", encaminé y realicé - gracias a la valiosa colaboración de sus investigadores y, de manera particular, de Manuela Sanna y Maurizio Martirano, pero también gracias a los programas de investigación ideados y realizados junto con Vanna Gessa Kurotschka de la Universidad de Cagliari, pródiga de consejos y sugerencias- una serie de congresos en los que han participado los mayores estudiosos italianos y extranjeros de Vico y que han constituido los materiales de una serie de volúmenes que han enriquecido las colecciones del Centro. Menciono aquí solo una parte de ellos: La filosofia pratica tra metafisica e antropologia nell'età di Wolff e Vico de 1999 (con un ensayo mío sobre Filosofia "civile" e filosofia "pratica" in Vico); Il sapere poetico e gli universali fantastici. La presenza di Vico nella riflessione filosofica contemporanea de 2004 (con una intervención mía acerca de Vico: narrazione storica e narrazione fantastica). En varias ocasiones, seguí y argumenté mejor este fil rouge interpretativo basado en los aspectos constitutivos de la filosofía "dualista" de Vico. En esta línea de investigación se insertan varias intervenciones mías en torno a las complejas relaciones en Vico entre poesía e historia, entre historia y fantasía, en torno a la posibilidad de fundamentar una "racionalidad otra" (tal como se puede ver en un ensayo de 2012 ahora reimpreso en un volumen que algunos discípulos me han dedicado para celebrar mis 70 años y que muy significativamente se titula In dialogo con Vico). En realidad, el tema ya estaba presente en uno de los capítu- 
los de mi monografía publicada en Alemania en el año 2002 (Metaphysik, Poesie und Geschichte. Über die Philosophie von Giambattista Vico). La misma está construida en la estela de un recorrido que atestigua, una vez más, la pluralidad de claves de lectura de la obra viquiana y para ello basta parar mientes en los temas de los capítulos: el capítulo inicial (Die Geschichte als philosophisches Problem. Metaphysik, Zeit, Wahrheit und Faktizität), el que plantea el problema de la relación entre filosofía y filología, el de la educación como condición necesaria para la instauración de una justicia civil, el que está dedicado al nexo entre política y filosofía práctica y, finalmente, el que trata del orden de la comunidad y del "sentido común" de la diferencia. Unos años más tarde, en 2009, salía mi pequeño volumen acerca de L'infinito nella storia. Saggi su Vico, que nació de la invitación que el amigo y colega Vincenzo Vitiello, estudioso autorizado del filósofo napolitano, me hizo para que publicara, en una colección que él dirigía para las "Edizioni Scientifiche Italiane", algunas páginas dedicadas a la estrecha relación entre el momento teorético y el histórico-práctico de la filosofía de Vico. Con este objetivo, reanudé -en una confrontación intensa y provechosa con Vitiello, de la que son prueba tanto la presencia en el apéndice de dos reseñas mías de sus estudios viquianos como el epílogo que él quiso escribir- a partir de Vico, un hilo conductor que desde el comienzo ha caracterizado, si se me permite decirlo así, mi perspectiva filosófica. Me refiero a mi pertenencia firme al historicismo crítico (no idealista, antifinalista y problemático) y, por ende, a la profundización teorética en el problema de la historicidad en su relación entre temporalidad y facticidad, de un lado, y a la continua búsqueda historiográfica de la génesis y el desarrollo, a través de las filosofías europeas, del historicismo y de sus variantes, del otro.

Son temas que he revisado y repensado (y que todavía hoy me impulsan a leer y a releer los escritos viquianos) en mi, a estas alturas, larga carrera y, quizás por esto, en el volumen que me dedicaron mis alumnos, los ensayos aparecen agrupados según una secuencia que jalona las fases del acercamiento a "mis Vico": la relación entre metafísica, filosofía civil e historia; el nexo entre filología y razón poética y, finalmente, un Vico a la altura de algunas temáticas ético-políticas de la contemporaneidad (mientras que la última parte propone nuevamente las fases de mi investigación sobre la presencia viquiana en el mundo ibérico, que, por otra parte, contiene un ensayo que creo que constituye un caso único -salvo mentís, que recibiría con mucho gusto- en torno a Forme e figure dell'ingegno tra Cervantes e Vico). En fin, la obra viquiana sigue siendo para mí un modelo valioso al cual dirigirse, como a todo clásico del pensamiento, pero no para desvirtuar, contra el rigor filológico, su perspectiva filosófica originaria, sino para captar motivos críticos y reflexiones, conceptos y análisis, "en perspectiva", según la acertada definición de los editores de mi In dialogo con Vico. La perspectiva significa hallar -sin intentar actualizaciones forzadas e improbables- elementos de reflexión y motivos críticos 
que, más allá de su génesis y de su raigambre histórica, logran indicar todavía hoy "nuevos senderos" a lo largo del recorrido de la filosofía y de sus "prácticas". Me refiero al modo como Vico llega a definir el concepto de Civitas/Ciudadanía -que constituye el meollo de unas páginas que escribí en el año 2001 y que luego repensé por el año 2016 en la cumbre de la crisis dramática de las migraciones y de la xenofobia resurgente- como lugar de actuación de la justitia aequatrix que no solo es principio jurídico-formal, sino sobre todo histórico-antropológico. Ya no más la línea de la utilidad "madre del derecho", según la perspectiva maquiaveliana y hobbesiana, sino «ocasión de la sociedad humana». Por ese rumbo, Vico alcanza una idea de sociedad política y civil, la civitas, como la «más amplia de las universalidades políticas». Es el Vico que, construyendo y argumentando la función de "otra vía" en la construcción de lo humano y de sus formas de vida, señala sus métodos, teorías y prácticas en la esencia originaria de lo humano: la poesía y el ingenio como instrumento capaz de poner en una relación "virtuosa" razón, sentido, pasiones y voluntad. De esta forma, a la luz de estos motivos inspiradores, además de las páginas en las que he reconstruido el concepto de ciudadanía y en la misma línea del hallazgo de los lugares de la otra modernidad del pensamiento viquiano, escribí en el año 2005 una intervención acerca de La facoltà della mente "rintuzzata" dentro il corpo, publicada en Il Laboratorio del ISPF y un artículo del año 2008 sobre Universalismo etico e differenza, publicado en BCSV. Pero el ensayo en el que, según creo yo, intenté dar, al mismo tiempo, fundamentación teórica y base histórico-documental a este recorrido "en perspectiva" es el del año 2012 -publicado en un volumen editado por Marco Vanzulli que recopila las ponencias pronunciadas en el congreso Razionalità e modernità in Vico, que tuvo lugar en la Universidad de Milán-Bicocca en junio de 2011, que lleva por título Per una critica della ragione poetica: l' "altra razionalità" di Vico. Aquí parto de una crítica a la tesis propuesta por el filósofo y politólogo americano Mark Lilla, partidario, en un libro suyo, de un Vico antimoderno y anti-ilustrado y que está basada en la convicción de que la obra del filósofo napolitano es totalmente inconciliable con las ideas de razón crítica y de libertad y que por eso mismo se colocaría en el contexto de las ideas de orden y de autoridad. Refiriéndome precisamente a algunas de las investigaciones más recientes en torno a la génesis de las ideas ilustradas (cito entre otros a Daniel Roche y a Vincenzo Ferrone), he considerado como una de las características de la Ilustración la «difusión de una antropología histórico-cultural que interroga a la otra humanidad», y que halla sus referencias en Buffon, Rousseau, Voltaire, Smith y Vico. Baste con citar las primeras líneas de la dedicatoria que es posible leer al principio de la Scienza nuova de 1725:

“Alle Accademie dell'Europa / le quali / in quest'età illuminata in cui / nonché le favole / e le volgari tradizioni / della storia gentilesca / ma 
ogni qualunque autorità / de' più riputati filosofi / alla critica di severa ragione / si sottomette [...] questi principi di altro sistema / $i$ quali ne ha meditato / con la discoverta / d'una nuova scienza della natura delle nazioni $[\ldots]$ Giambattista Vico [...] riverentemente indirizza". ${ }^{1}$

De esta manera, demasiado rápida y resumida, creo haber dado cuenta de "mis" tantos Vico y, si echo atrás la mirada hacia los cincuenta años de trato con sus páginas, hallo altos y bajos, interpretaciones más o menos convincentes, conclusiones a veces discutibles, intuiciones otras veces originales. Pero también sé a ciencia cierta que hallaré "en perspectiva" a otro Vico mío.

[Traducción del italiano por María Lida Mollo]

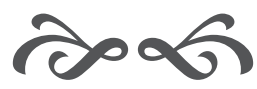

1. «A las Academias de Europa, que en esta época ilustrada en la que, además de las fábulas y las tradiciones vulgares de la historia gentil, también cualquier autoridad de los más reputados filósofos se somete a la crítica de la severa razón [...], Giambattista Vico [...] dedica con reverencia estos principios de otro sistema que ha meditado con el descubrimiento de una nueva ciencia de la naturaleza de las naciones [...]». [N.E.] 
350 